\title{
Performance Study of Silica-on-Silicon Based Multimode Interference (MMI) Optical Coupler
}

\author{
A. Zahed CHOWDHURY* \\ Department of Applied Physics, Electronics and Communication Engineering, University of Chittagong, \\ Chittagong-4331, Bangladesh \\ "Corresponding author: A. Zahed CHOWDHURY_E-mail: zahedcu12@gmail.com
}

\begin{abstract}
In recent years, the silica-on-silicon based multimode interference (MMI) optical waveguide is an interesting research topic. It is being advanced various researches on the silica based MMI coupler. This paper represents the considerations of the optimal design of the silica-on-silicon based MMI optical coupler for better performance. For that, we have illustrated the simulation results on a particular case of the $4 \times 4$ silica-on-silicon based MMI coupler. From the simulation results, it is seen that the performance of the MMI coupler depends on multiple width and length combinations of the MMI waveguide. The results also show that the width of the multimode waveguide could not be too small or too large for optimal performance, and at the widths, $100 \mu \mathrm{m}, 120 \mu \mathrm{m}$ and $130 \mu \mathrm{m}$, the performance could be optimized and be almost $0.62-0.64$ in a given length range. Finally, the results have been compared with the optical coupler presently available in the market and show that the silica-on-silicon based MMI coupler is much more efficient in terms of losses and the performance associated with it and the size of the coupler.
\end{abstract}

Keywords: Optical coupler, planar lightwave circuits (PLCs), silica-on-silicon waveguide, multimode interference (MMI) coupler, performance (PF)

Citation: A. Zahed CHOWDHURY, "Performance Study of Silica-on-Silicon Based Multimode Interference (MMI) Optical Coupler," Photonic Sensors, 2014, 4(1): 34-42.

\section{Introduction}

The ability of optical fiber couplers to transfer light from one fiber to another makes it one of the key components of an optical fiber system. A fiber optic coupler can also be used as a power splitter that allows the light signal to be shared between fibers. Generally, three coupler configurations can be identified such as the bi-directional coupler, star coupler, multimode interference coupler (MMI). Whereas, the bi-directional coupler can only split optical power between two waveguides, and the star coupler and MMI coupler can split the power among more than two waveguides [1]. Now optical couplers are used in photonic integrated circuits [also called planar lightwave circuits (PLCs) or integrated optoelectronic devices] when it is necessary to couple light between different waveguides. These types of couplers have been realized using directional couplers. Unfortunately, these components have been found to be sensitive to the wavelength, fabrication tolerances, and polarization state of light. [2] However, many of these problems have been solved, leaving PLCs with four major advantages: the enhanced functionality, very low losses, compactness, and potential for the

Received: 1 May 2013 / Revised version: 15 May 2013

(C) The Author(s) 2013. This article is published with open access at Springerlink.com

DOI: $10.1007 / \mathrm{s} 13320-013-0117-4$

Article type: Regular 
mass production. Generally, PLCs based optical waveguides and devices can be fabricated by using different materials including $\mathrm{LiNbO}_{3}[3], \mathrm{SiO}_{2}[4,5]$, silicon-on-insulator (SOI) [6, 7], polymer [8], InP [9, 10]. Each material has advantages and disadvantages for a specific required function. Bulk silica $\left(\mathrm{SiO}_{2}\right)$ and silica-on-silicon $\left(\mathrm{SiO}_{2} / \mathrm{Si}\right)$ are by far the most common materials used to manufacture PLCs, due to their refractive index matching with the silica-based optical fiber [11]. Table 1 provides a summary of the material types available for waveguide manufacturing [12].

Table 1 Summary of the different materials used for the PLC [12].

\begin{tabular}{|c|c|c|c|}
\hline Material & Waveguide Structure & Advantage & Disadvantage \\
\hline $\mathrm{LiNbO}_{3}$ & $\mathrm{Ti}^{+}$ & $\begin{array}{l}\text { High } \\
\text { coefficient, electro-optic } \\
\text { effect, excellent hon-linear } \\
\text { speed modulation }\end{array}$ & High loss \\
\hline $\mathrm{SiO}_{2}$ & Si substrate & Very low loss & \begin{tabular}{|ll} 
Suitable only \\
passive \\
functions
\end{tabular} \\
\hline $\mathrm{Si}$ & $\frac{\mathrm{SiO}_{2}}{\text { Si substrate }}$ & $\begin{array}{l}\text { High refractive index } \\
\text { contrast, high integration } \\
\text { density, compatible with } \\
\text { Si electronics }\end{array}$ & $\begin{array}{l}\text { Indirect band } \\
\text { gap, unsuitable } \\
\text { for lighting }\end{array}$ \\
\hline InP & In $\mathrm{P}$ & $\begin{array}{l}\text { Direct band gap, good for } \\
\text { light emitters, high speed } \\
\text { modulation lighting }\end{array}$ & $\begin{array}{l}\text { High cost, } \\
\text { complex } \\
\text { technology }\end{array}$ \\
\hline Polymer & $\begin{array}{l}\text { Polymer } \\
\text { Substrate }\end{array}$ & $\begin{array}{l}\text { Ease of fabrication, low } \\
\text { cost, good electro-optic, } \\
\text { thermal-optic performance }\end{array}$ & Stab \\
\hline
\end{tabular}

The basic functions in PLCs are the generation, guiding, splitting, multiplexing, amplification, switching and detection of the light signal. Different types of optical couplers such as $1 \times 4,1 \times 8$, and $1 \times 32$ have been made compact on a chip using the Y-branches [13], arrayed waveguide gratings (AWG) [14, 15], matrix switches [16], star couplers [17], Mach-Zehnder interferometer [18] or MMI couplers [19-21] which are typically based on the PLC technology. The PLC based devices are superior to conventional fused-fiber type splitters in terms of the low cost and mass producibility. PLC type optical couplers have already been put into the practical use in fiber-to-the-home (FTTH) systems that have been considered to be the ultimate solution for future broadband access networks, and their long term reliability for telecommunications has already been established.

MMI couplers have been developed rapidly in recent years since its first introduction by Ulrich and Ankele [22, 23]. MMI couplers are widely used in many PLCs, such as power splitters [24], ring lasers [12], optical switches [25], and wavelength division multiplexers/ demultiplexers [26-28].

Based on the self-imaging principle, MMI couplers offer the advantages of the compact size, low cross-talk, and low power imbalance. Compared to directional couplers and $\mathrm{Y}$ splitters, MMI couplers show superiority in scalability, since they do not need to be cascaded in order to achieve large port counts [12]. The multimode interference principle (also known as the self-imaging theory) is developed theoretically based on high-index-contrast optical waveguides using the strong guiding approximation. For that reason, high-index-contrast structures such as $\mathrm{InGaAsP} / \mathrm{InP}$ and GaAs/AlGaAs are normally used to realize the MMI devices.

But recently, some research works have been done on low-index-contrast optical waveguide MMI devices which are based on silica-on-silicon waveguides, since silica-on-silicon waveguides have several advantages over other optical waveguides such as [29]

(1) Silica-on-silicon light wave circuits have a glass composition similar to that of optical fibers.

(2) Silica waveguides can be fabricated using various methods.

(3) Their simple core structures.

(4) Low propagation loss.

(5) Providing perfect field matching to that of optical fibers.

So, silica-on-silicon waveguides are more attractive from both research and commercial perspectives.

Here, we have mentioned current researches that have been studied on silica-on silicon MMI devices in considerable details such as

(1) A 3-dB two-mode-interference coupler was 
proposed based on silica waveguides in 1992 [30].

(2) $1 \times 64$ MMI splitters were designed and evaluated in 1995 [31]. The loss of the devices was $0.5 \mathrm{~dB}$, and the uniformity was $1.7 \mathrm{~dB}$.

(3) In 1997, $1 \times N$ MMI couplers were fabricated in silica-on silicon waveguides [32]. $1 \times 2,1 \times 4$ and $1 \times 8$ MMI couplers were realized with losses of $0.7 \mathrm{~dB}, 0.9 \mathrm{~dB}$ and $1.3 \mathrm{~dB}$.

(4) In 2002, genetic algorithms were introduced to do an optimal design of MMI couplers based on weakly guiding waveguides [33].

(5) In 2003, the access waveguide position of weakly guiding MMI couplers was discussed, and the optimal performance devices were obtained [34]. In 2004, a three-dimensional weakly guiding MMI coupler based on ion exchange waveguides was discussed [35].

(6) In 2006, $N \times N, 1 \times K$ MMI couplers based on Ge-doped silica-on-silicon optical waveguides were designed and fabricated successfully using hollow cathode plasma enhanced chemical vapour deposition (HC-PECVD) and reactive-ion etching (RIE) [29].

Hence, it is evident that the MMI couplers based on the silica-on-silicon system is an interesting topic in the integrated optical circuit research. Since the principle of the self-imaging theory in multimode interference established on strong guiding (high-index-contrast waveguides) approximation is not well satisfied in low-index-contrast systems such as silica-on-silicon waveguides, we have studied to realize good performance MMI couplers based on silica-on-silicon structures.

\section{Performance study of Silica-on-Silicon based MMI device}

The theory of self-imaging in multimode optical waveguides has been the subject of several studies [36-39]. The analysis is based on the strong guiding approximation that is satisfied in the high-index-contrast structures. Although silica-on-silicon light wave circuits are low-index-contrast structures, good understanding of the fundamental theoretical analysis is helpful to design silica-on-silicon multimode interference (MMI) devices. The results of the self-imaging theory could be thought as an approximation for the low-index-contrast structures [29]. Figure 1 shows a schematic of an $N \times N$ MMI coupler with its related 2D model. As shown in Fig. 1, an MMI coupler can be made of the silica buried waveguide with a doped core layer and undoped cladding layers. The transverse direction of the silica waveguide is designed to be single mode. In the case of 3D waveguides, an equivalent $2 \mathrm{D}$ representation can be made by techniques such as the effective index method or the spectral index method [37].

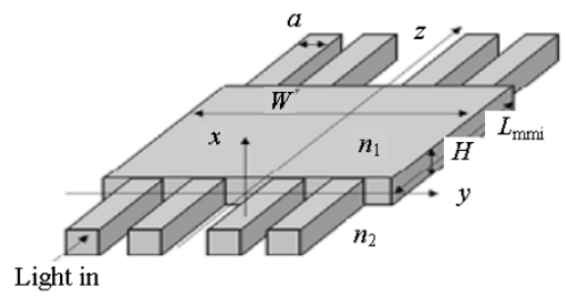

(a) 3D structure

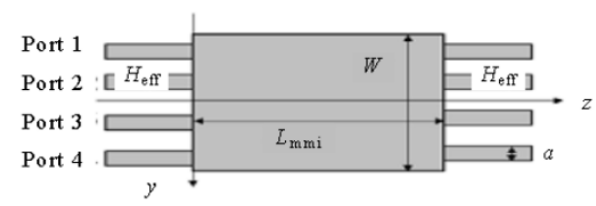

(b) 2D model (2D structure)

Fig. 1 An $N \times N$ silica MMI coupler and its related 2D model $(N=4)$ [the width and the length of the multimode waveguide are $W$ and $L_{\text {mmin }}$, the core effective index $n_{\text {eff }}$ of the correspondent 2D model can be found by the mode index (the propagation constant divided by the free-space wavenumber $\beta / k_{\mathrm{o}}$ ) in the slab along the $x$ direction, the cladding effective index $n_{2}$ is equal to the cladding index in the $3 \mathrm{D}$, and the thickness of the guiding layer and the width of the access waveguide are both $a$ [29]].

In this section, we have pointed out that the length of the silica-on-silicon based MMI waveguide could be optimized for better performance. As stated in [29], the multimode section can support the maximum $M+1$ number of modes. For each mode $v$, the dispersion relation is 
given by

$$
\beta_{v}=\beta_{0}-\frac{v(v+2) \pi}{3 L_{\pi}}
$$

where

$$
L_{\pi}=\frac{\pi}{\beta_{0}-\beta_{1}} \approx \frac{4 n_{\mathrm{eff}} W^{2}}{3 \lambda_{0}}
$$

where $L_{\mathrm{mmi}}$ is the length of the multimode waveguide and can be estimated as

$$
L_{\mathrm{mmi}}=\frac{p}{N}\left(3 L_{\pi}\right)=\frac{3 L_{\pi}}{N}
$$

with $p=1$ for shortest devices in (3).

But $L_{\pi}$ is related not only to the propagation constant of the two lowest order modes but also to the propagation constant of the fundamental and other higher orders

$$
L_{\pi}(v)=\frac{v(v+2) \pi}{3\left(\beta_{0}-\beta_{v}\right)} \quad v=1,2, \cdots, v_{\max } .
$$

$L_{\pi}$ is estimated as a series of the minimum values given in terms $\beta_{0}$ and $\beta_{v}$ and the maximum values in terms of $\beta_{0}$ and $\beta_{v_{\max }}$

$$
L_{\pi \min }=L_{\pi}(1)=\frac{\pi}{\beta_{0}-\beta_{1}}
$$

and

$$
L_{\pi \max }=L_{\pi}\left(v_{\max }\right)=\frac{v_{\max }\left(v_{\max }+2\right) \pi}{3\left(\beta_{0}-\beta_{v_{\max }}\right)} .
$$

Hence, these series values of $L_{\pi}(v)$ result in series values of $L_{\mathrm{mmi}}$ that can be in a range between

$$
L_{\text {mmi min }}=\frac{3 L_{\pi \min }}{N}
$$

and

$$
L_{\text {mmi max }}=\frac{3 L_{\pi \max }}{N} .
$$

Now it is noted that there are two important features for MMI based devices such as the insertion loss (LS) and uniformity (UF). With the range of $L_{\mathrm{mmi}}$, the loss and uniformity can be valued to find optimal performance of the MMI device.

The performance of MMI based devices have been studied on these features. As defined in [29], a new parameter to describe the overall performance of the silica based MMI coupler is defined.
This parameter is associated with LS and UF. It is called the performance (PF) that can be expressed as

$$
P F=10^{-\sum_{t} \frac{U F}{10}-\sum_{t} \frac{L S}{10}}
$$

where $t=1,2, \cdots, N / 2$ when $N$ is even, and $t=1$, $2, \cdots,(N+1) / 2$ when $N$ is odd.

Since the MMI coupler has multiple input ports, a summation should be done over these ports.

In case of symmetry, summation over all the input ports is not necessary. From (9), it can be seen that the smaller uniformity and loss give the larger performance. The best performance occurs when $P F$ equals 1 , and the worst performance occurs when $P F$ is 0. It was reported [29] that the performance of an MMI coupler depended on the width and length of the multimode waveguide section. It is seen that the performance varies within a specified range of the length at a specific width of the waveguide section. Therefore, the width and length of the MMI section can be selected as parameters to design an $N \times N$ MMI coupler.

\section{Simulation results and discussions}

In this paper, we illustrate the particular case of a $4 \times 4$ MMI coupler as an example and analyze the performance for the design of an $N \times N$ silica MMI device. In our study, the parameters were selected as the earlier analysis of the non-optimized structure.

That is, the wavelength is $1.55 \mu \mathrm{m}$, the refractive indices of the core and cladding are 1.46 and 1.456, respectively, the thickness of the guiding layer and the width of the access waveguide are both $6 \mu \mathrm{m}$, and the selected widths of the multimode waveguide are $90 \mu \mathrm{m}, 100 \mu \mathrm{m}, 110 \mu \mathrm{m}, 120 \mu \mathrm{m}, 130 \mu \mathrm{m}$ and $140 \mu \mathrm{m}$. For different widths of the multimode waveguide, $L_{\mathrm{mmi}}$ varies within the range found using (7) and (8). Calculations are done for widths of $90 \mu \mathrm{m}, 100 \mu \mathrm{m}, 110 \mu \mathrm{m}, 120 \mu \mathrm{m}, 130 \mu \mathrm{m}$, and $140 \mu \mathrm{m}$, which corresponded to $10,11,12,13,14$ and 15 modes respectively in the multimode waveguide. On the basis of the above parameters, 
the simulation results are analyzed.

The PF parameter of a $4 \times 4$ device with different lengths and widths of the multimode waveguide is shown in Fig. 2. From the simulation results, it is seen that there are multiple length/width combinations for which there exists similar optimal
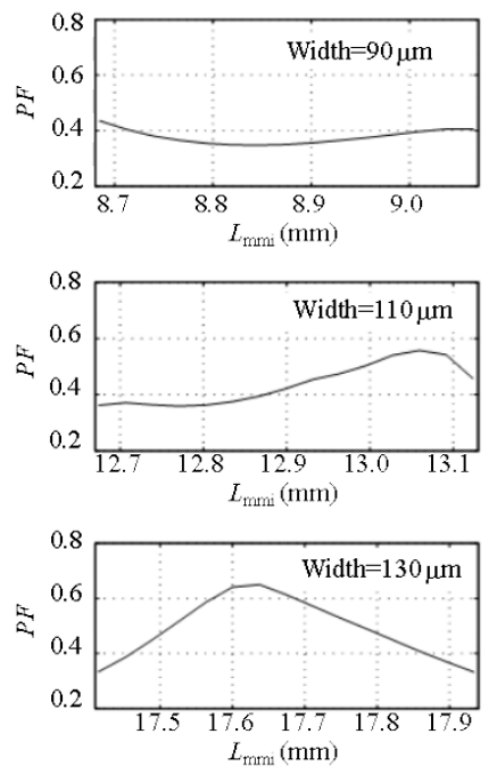

performance of the coupler. When the width is $120 \mu \mathrm{m}$ and the length is $15.25 \mathrm{~mm}$, the performance is 0.64 which is similar to the case for which the width is $130 \mu \mathrm{m}$ and the length is $17.64 \mathrm{~mm}$. This means that optimal performance can be achieved for several choices of the multimode waveguide size.
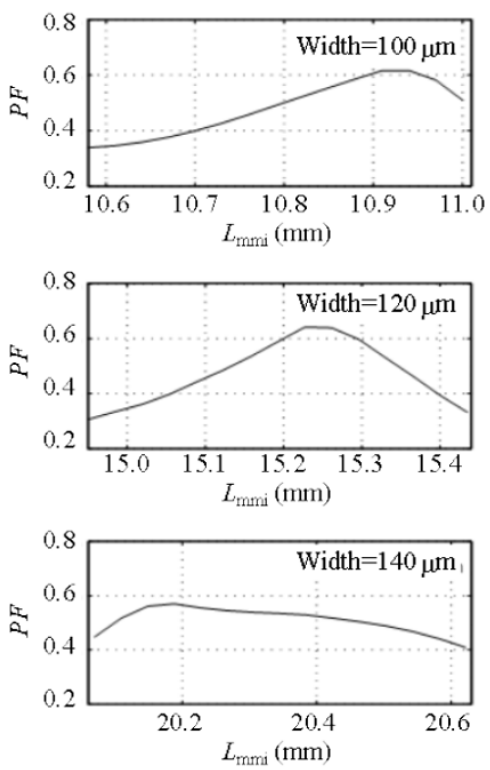

Fig. 2 Performance variation for different widths and lengths for a $4 \times 4$ MMI coupler [29].

In case of the width of $110 \mu \mathrm{m}$ and $140 \mu \mathrm{m}$, the performance changes slightly, and the optimal performance can be achieved in the specified range.

Again when the width is $90 \mu \mathrm{m}$, the performance of a device drops slightly and then increases slightly in the specified range, and the overall performance is poor. These results show that the width of the multimode waveguide can not be too small or too large for optimal performance.

We have also studied that the PF is associated with the loss and uniformity of a device with the $4 \times 4$ MMI coupler, and it is pointed out that the loss and uniformity of a device are different for different lengths and widths as illustrated in Fig. 3. From the simulation results for the widths of $90 \mu \mathrm{m}, 120 \mu \mathrm{m}$, $140 \mu \mathrm{m}$, it is seen that for the width of $90 \mu \mathrm{m}$, when either the port 1 or the port 4 is used as the input, the excess loss and uniformity are around $0.75 \mathrm{~dB}$ and $1.5 \mathrm{~dB}$ at the length of $8.9 \mathrm{~mm}$, and when either the port 2 or the port 3 is used, the excess loss and uniformity are around $0.49 \mathrm{~dB}$ and $1.8 \mathrm{~dB}$ at the length of $8.9 \mathrm{~mm}$. Since the uniformity exceeds the loss, the performance can not be improved in this case and is 0.38 . For the width of $120 \mu \mathrm{m}$, when either the port 1 or the port 4 is used as the input, the excess loss and uniformity are around $0.64 \mathrm{~dB}$ and $0.31 \mathrm{~dB}$ in a given range at a length of around $15.25 \mathrm{~mm}$, and when either the port 2 or the port 3 is used, the excess loss and uniformity are around $0.66 \mathrm{~dB}$ and $0.33 \mathrm{~dB}$ in a given range at a length of around $15.25 \mathrm{~mm}$. So the performance is significantly better for this width and is 0.64 .

For the width of $140 \mu \mathrm{m}$, when either the port 1 or the port 4 is used as the input, the excess loss and uniformity are around $0.57 \mathrm{~dB}$ and $0.36 \mathrm{~dB}$ in a given range at a length of around $20.35 \mathrm{~mm}$, and when either the port 2 or the port 3 is used, the excess loss and uniformity are around $0.87 \mathrm{~dB}$ and $0.98 \mathrm{~dB}$ in a given range at a length of around $20.35 \mathrm{~mm}$. Here, the performance is not significantly 
improved by adjusting the length within the given range and is 0.56 . Table 2 provides a summary of the simulation results for the $4 \times 4 \mathrm{MMI}$ coupler.

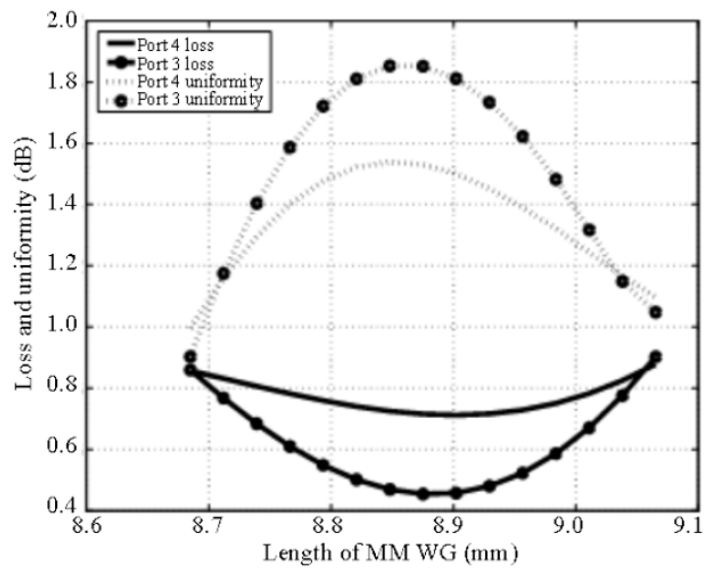

(a)

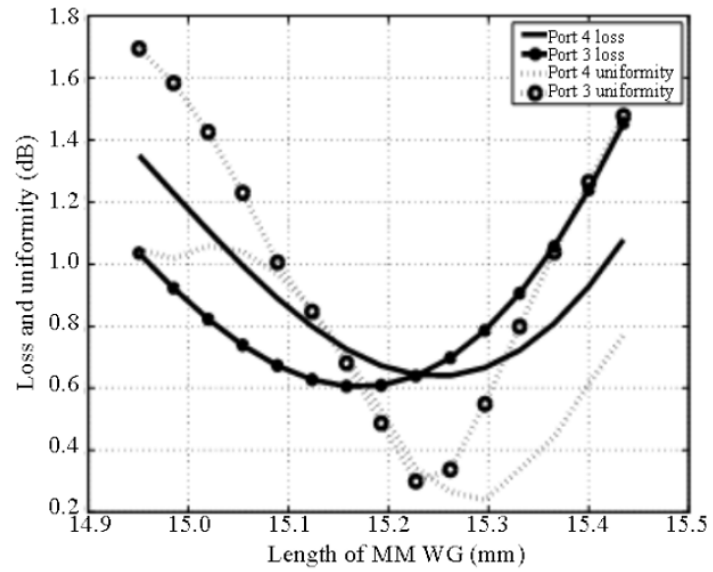

(b)

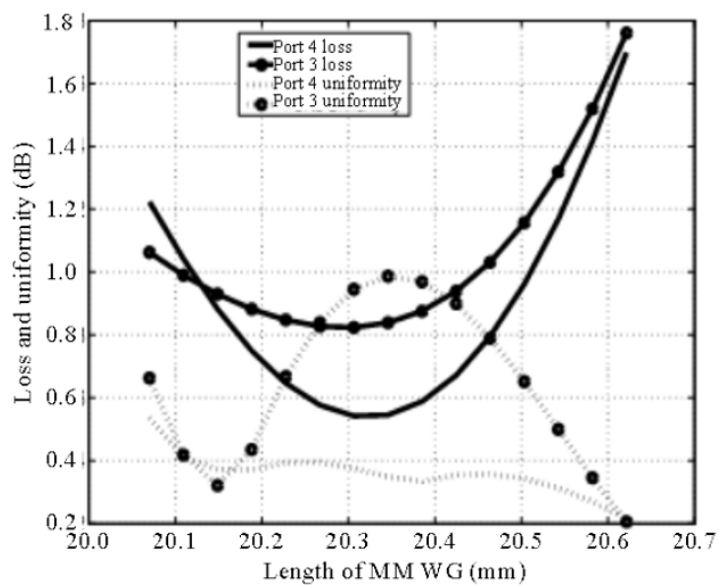

(c)

Fig. 3 Variation of loss and uniformity with the length of the multimode waveguide (MM WG) when (a) the width is $90 \mu \mathrm{m}$, (b) the width is $120 \mu \mathrm{m}$, and (c) the width is $140 \mu \mathrm{m}$. [29].
Table 2 Summary of the simulation results for the $4 \times 4$ MMI coupler.

\begin{tabular}{|c|c|c|c|c|c|}
\hline \multirow[b]{2}{*}{ Width/length } & \multicolumn{2}{|c|}{ Port 1 or 4} & \multicolumn{2}{|c|}{ Port 2 or 3} & \multirow[b]{2}{*}{$\begin{array}{l}\text { Performance } \\
\quad(\mathrm{PF})\end{array}$} \\
\hline & \begin{tabular}{|l|} 
Insertion \\
loss (dB)
\end{tabular} & \begin{tabular}{|l} 
Uniformity \\
(dB)
\end{tabular} & \begin{tabular}{|l|} 
Insertion \\
loss (dB)
\end{tabular} & \begin{tabular}{|l} 
Uniformity \\
(dB)
\end{tabular} & \\
\hline $90 \mu \mathrm{m} / 8.9 \mathrm{~mm}$ & 0.75 & 1.50 & 0.49 & 1.80 & 0.38 \\
\hline $\begin{array}{c}120 \mu \mathrm{m} / \\
15.25 \mathrm{~mm}\end{array}$ & 0.64 & 0.31 & 0.66 & 0.33 & 0.64 \\
\hline $\begin{array}{c}140 \mu \mathrm{m} / \\
20.35 \mathrm{~mm}\end{array}$ & 0.57 & 0.36 & 0.87 & 0.98 & 0.56 \\
\hline
\end{tabular}

Form these results, it is seen that the loss can always be improved within the range but the uniformity has a different behavior. Whether uniformity is improved or deteriorated depends on the device width.

Based on the results, it could be concluded that if both the loss and uniformity need to be optimized, not only the length but also the width of the multimode waveguide should be adjusted. Using the results in Fig. 3, an optimal design for both low loss and good uniformity can be found. With the width of the multimode waveguide fixed at $120 \mu \mathrm{m}$, the optimal length is found to be approximately $15.25 \mathrm{~mm}$.

The results at the width of $120 \mu \mathrm{m}$ are compared with the case studied in $[31,33]$ where (3) from the self-imaging theory is used to find the length of the multimode waveguide, $L_{\mathrm{mmi}}=14.95 \mathrm{~mm}$, and the access waveguide positions are $\pm 47.30 \mu \mathrm{m}$ and $\pm 15.80 \mu \mathrm{m}$. When the light is input into the port 1 or the port 4 , the loss and uniformity are determined to be $1.354 \mathrm{~dB}$ and $1.048 \mathrm{~dB}$, respectively at the width of $120 \mu \mathrm{m}$, and when light is input into the port 2 or the port 3, the loss and uniformity are $1.037 \mathrm{~dB}$ and $1.696 \mathrm{~dB}$, respectively at the width of $120 \mu \mathrm{m}$. In this case, the PF of the device is 0.307 , where the width and length are not optimized. But using our proposed method, the value of the performance is improved by more than a factor of 2 .

Now under these considerations, we have compared our proposed coupler with couplers available in the market. A typical standard for the $N \times N$ planar coupler/splitter available in the market is presented in Table 3 . It is seen that for a typical 
$(4 \times 4)$ coupler, the loss and uniformity are around $7.0 \mathrm{~dB}$ and $0.5 \mathrm{~dB}$, respectively.

Table 3 A typical standard for $N(1) \times N$ coupler/splitter (source: www.optokon.com)[40].

\begin{tabular}{|c|c|c|c|c|}
\hline Specifications & $4(1) \times 4$ & $8(1) \times 8$ & $16(1) \times 16$ & $32(1) \times 32$ \\
\hline $\begin{array}{c}\text { Insertion } \\
\text { loss }(\mathrm{dB}) \cdot \max \end{array}$ & 7.0 & 10.3 & 13.4 & 16.8 \\
\hline Uniformity $(\mathrm{dB})$ & $<0.5$ & $<0.5$ & $<0.8$ & $<0.9$ \\
\hline $\begin{array}{c}\text { Operating } \\
\text { wavelength }(\mu \mathrm{m})\end{array}$ & \multicolumn{4}{|c|}{$1.25-1.65$} \\
\hline Max. PDL (dB) & \multicolumn{2}{|c|}{$<0.15$} & \multicolumn{2}{|c|}{$<0.2$} \\
\hline $\begin{array}{l}\text { Return loss } \\
(\mathrm{dB})\end{array}$ & \multicolumn{4}{|c|}{$>55$} \\
\hline Directivity $(\mathrm{dB})$ & \multicolumn{4}{|c|}{$>55$} \\
\hline $\begin{array}{c}\text { Standard } \\
\text { package }(\mathrm{mm}) \\
\text { BFF type }\end{array}$ & \multicolumn{2}{|c|}{$44 \times 4 \times 4$} & \multicolumn{2}{|c|}{$55 \times 7 \times 4$} \\
\hline
\end{tabular}

In this case, the PF is 0.18 . So the comparison of our designed coupler with the presently available coupler shows that our designed coupler is much more efficient in terms of the loss and performance associated with it and the size of the coupler.

\section{Conclusions}

We have focused on a method that is based on finding the optimal performance by changing the geometrical parameters of the MMI couplers. In this method, the width and length of the multimode waveguide are adjusted to achieve the optimal device performance. It is found that the length of the multimode waveguide could vary in a well-defined range for better performance.

This range is related to the propagation constant spacing of the fundamental and higher modes of the multimode waveguide. Finally, we have proposed a suitable design for a $4 \times 4$ silica-on-silicon based MMI coupler. The parameters are that the length and the width are $15.25 \mathrm{~mm}$ and $120 \mu \mathrm{m}$, the thickness is $6 \mu \mathrm{m}$, and the loss and uniformity are around $0.66 \mathrm{~dB}$ and $0.33 \mathrm{~dB}$, respectively. The performance is 0.64 . While the standard package of the couplers/splitters available in the market is around $40 \mathrm{~mm} \times 4 \mathrm{~mm} \times$ $4 \mathrm{~mm}$, and the loss and uniformity associated with a typical $4(1) \times 4$ coupler/splitter are around $7.0 \mathrm{~dB}$ and $0.5 \mathrm{~dB}$, respectively. In this case, the performance is 0.18 . So the proposed coupler is much more efficient than the couplers available in the market. But as in our study, the performance of the silica-on-silicon based MMI coupler was analyzed for a single wavelength of $1.55 \mu \mathrm{m}$, hence, we need to study its performance for different wavelengths (such as $\mathrm{C}$ band) if it is implemented in the optical network like the dense wavelength-division multiplexing (DWDM) system.

\section{Acknowledgement}

The author would like to thank Professor Dr. Rezaul Huque Khan and Dr. Sankar Lal Saha for their sincere co-operation.

Open Access This article is distributed under the terms of the Creative Commons Attribution License which permits any use, distribution, and reproduction in any medium, provided the original author(s) and source are credited.

\section{References}

[1] H. G. Van Zyl, "Modeling of integrated optic components for lightwave communications systems using the beam propagation method," M.Eng.dissertation, Rand Afrikaans University, Johannesburg, Republic of South Africa, 2001.

[2] K. Solehmainen, M. Kapulainen, M. Harjanne, and T. Aalto, "Adiabatic and multimode interference couplers on silicon-on-insulator," IEEE Photonics Technology Letters, vol. 18, no. 21, pp. 2287-2289, 2006.

[3] R. Ramponi, M. Marangoni, and R. Osellame, "Dispersion of the ordinary refractive-index change in a proton-exchanged $\mathrm{LiNbO}_{3}$ waveguide," Applied Physics Letters, vol. 78, no. 15, pp. 2098-2100, 2001.

[4] Y. Li and C. Henry, "Silica-based optical integrated circuits," IEEE Proceedings in Optoelectronics, vol. 143, no. 5, pp. 263-280, 1996.

[5] A. Himeno, K. Kato, and T. Miya, "Silica-based planar lightwave circuits," IEEE Journal of Selected Topics in Quantum Electronics, vol. 4, no. 6, pp. 913-924, 1998.

[6] P. D. Trinh, S. Yegnanarayanan, F. Coppinger, and B. Jalali, "Silicon-on-insulator (SOI) phased-array wavelength multi/multiplexer with extremely low-polarization sensitivity," IEEE Photonics Technology Letters, vol. 9, no. 7, pp. 940-942, 
1997.

[7] A. Baby and B. R. Singh, "Improve design of 8-channel silicon-on-insulator (SOI) arrayed waveguide grating (AWG) multiplexer using tapered entry into the slab waveguides," Fiber and Integrated Optics, vol. 23, no. 5, pp. 365-373, 2004.

[8] J. Yang, Q. Zhou, and R. T. Chen, "Polymide-waveguide-based thermal optical switch usintotal-internal-reflection effect," Applied Physics Letters, vol. 81, no. 16, pp. 2947-2949, 2002.

[9] J. J. He, B. Lamontagne, A. Delâge, L. Erickson, M. Davies, and E. S. Koteles, "Monolithic integrated wavelength demultiplexer based on a waveguide rowland circle grating in InGaAsP/InP," IEEE Journal of Lightwave Technology, vol. 16, no. 4, 631-638, 1998.

[10] M. Takenaka and Y. Nakano, "InP photonic wire waveguide using InAlAs oxide cladding layer," Optics Express, vol. 15, no. 13, pp. 8422-8427, 2007.

[11] Alain Pham, Ph.D., "Planar lightwave circuits: an emerging market for refractive index profile analysis," Application note 053, Industrial and scientific division, EXFO electro-optical engineering Inc., Canada, 2004.

[12] Y. Shi, "Design, simulation of characterization of some planar lightwave circuits (PLC)," Ph.D. dissertation, KTH School of Information and communication Technology, Stockholm, Sweden, 2008.

[13] C. W. Hsu, H. L. Chen, and W. S. Wang, "Compact Y-branch power splitter based on simplified coherent coupling," IEEE Photonics Technology Letters, vol. 15, no. 8, pp. 1103-1105, 2004.

[14] M K. Smit and C. V. Dam, "Phasar based WDM devices: principles, design and applications," IEEE Journal of Selected Topics in Quantum Electronics, vol. 2, no. 2, pp. 236-250, 1996.

[15] H. Uetsuka, "AWG technologies for dense WDM applications," IEEE Journal of Selected Topics in Quantum Electronics, vol. 10, no. 2, pp. 393-402, 2004.

[16]S. Sohma, T. Watanabe, T. Shibata, and H. Takahashi, "Compact and low power consumption 16×16 optical matrix switch with silica based PLC technology," presented at Optical Fiber Communication Conference 2005, Anaheim, California, USA, Mar. 6-11, vol. 4, 2005.

[17] Y. Asahara, S. Nakayama, O. Maruyama, S. Ohmi, H. Sakai, and Y. Yoneda, "Design and characteristics of a demultiplex star coupler," presented at Optical Fiber Communication Conference 1998, New Orleans, Louisiana, USA, WQ7, Jan. 25, 1998.

[18] B. E. Little and T. Murphy, "Design rules for maximally flat wavelength-insensitive optical power dividers using Mach-Zehnder structures," IEEE Photonics Technology Letters, vol. 9, no. 12, pp. 1607-1609, 1997.

[19] L. B. Soldano and E. C. M. Pennings, "Optical multimode interference devices based on self-imaging: principles and applications," Journal of Lightwave Technology, vol. 13, no. 4, pp. 615-627, 1995.

[20] S. Y. Tseng, C. Fuentes-Hernandez, D. Owens, and B. Kippelen, "Variable splitting ratio $2 \times 2$ MMI couplers using multimode waveguide holograms," Optics Express, vol. 15, no. 14, pp. 9015-9021, 2007.

[21] Y. Shi and D. Dai, "Design of a compact multimode interference coupler based on deeply-etched $\mathrm{SiO}_{2}$ ridge waveguides," Optics Communications, vol. 271, no. 2, pp. 404-407, 2007.

[22] R. Ulrich, "Light-propagation and imaging in planar optical waveguides," Nouvelle Revue d'Optique, vol. 6, no. 5, pp. 253-264, 1975.

[23] R. Ulrich and G. Ankele, "Self-imaging in homogeneous planar optical waveguides," Applied Physics Letters, vol. 27, no. 6, pp. 337-339, 1975.

[24] L. B. Soldano, F. B. Veerman, M. K. Smit, B. Verbeek, A. H. Dubost, and E. C. M. Pennings, "Planar monomode optical couplers based on multimode interference effects," Journal of Lightwave Technology, vol. 10, no. 12, pp. 1843-1850, 1992.

[25] F. Wang, J. Yang, L. Chen, X. Jiang, and M. Wang, "Optical switch based on multimode interference coupler," IEEE Photonics Technology Letters, vol. 18, no. 2, pp. 421-423, 2006.

[26] M. R. Paiam and R. I. MacDonald, "A 12-channel phased-array wavelength multiplexer with multimode interference couplers," IEEE Photonics Technology Letters, vol. 10, no. 2, pp. 241-243, 1998.

[27] Y. Hibino, "Recent advances in high-density and large-scale AWG multi/demultiplexers with higher index-contrast silica-based PLCs," IEEE Journal of Selected Topics in Quantum Electronics, vol. 8, no. 6, pp. 1090-1101, 2002.

[28] A. Torsten, "Bragg grating-assisted MMI-coupler for add-drop multiplexing," Journal of Lightwave Technology, vol. 16, no. 8, pp. 1517-1522, 1998.

[29] Z. Jin, "Silica-on-silicon lightwave circuits based on multimode interference for optical communications," Ph.D. dissertation, University of New South Wales, 2006.

[30] F. B. Veerman, P. J. Schalkwijk, E. M. C. Pennings, M. K. Smit, and B. Verbeek, "An optical passive 3-dB TMI-coupler with reduced fabrication tolerance sensitivity," IEEE Journal of lightwave Technology, vol. 10, no. 3, pp. 306-311, 1992. 
[31] T. Rasmussen, J. K. Rasmussen, and J. H. Povisen, "Design and performance evaluation of 1-by-64 multimode interference power splitter for optical communications," IEEE Journal of lightwave technology, vol. 13, no.10, pp. 2069-2074, 1995.

[32] Q. Lai, M. Bachmann, and H. Melchior, "Low loss $1 \times N$ multimode interference couplers with homogeneous output power distributions realized in silica-on silicon materials," Electronics Letters, vol. 33, no. 20, pp. 1699-1700, 1997.

[33] Q. Wang, J. Lu, and S. He, "Optimal design of a multimode interference coupler using a genetic algorithm," Optics Communications, vol. 209, no. 1-3, pp. 131-136, 2002.

[34] F. Rooms, A. Morand, I. Schaner, P. Benech, and S. Blaize, "A complete physical approach to position the access waveguides of weakly confined multimode interference couplers," Optics Communications, vol. 221, no. 4-6, pp. 317-322, 2003.

[35] B. West and S. Honkanen, "MMI devices with weak guiding designed in three dimensions using a genetic algorithm," Optics Express, vol. 12, no. 12, pp.
2716-2722, 2004.

[36] R. Ulrich and T. Kamiya, "Resolution of self-images in planar optical waveguides," Journal of the Optical Society of America, vol. 68, no. 5, pp. 583-592, 1978.

[37] L. Soldano and E. Pennings, "Optical multi-mode interference devices based on self-imaging: principles and applications," Journal of Lightwave Technology, vol. 13, no. 4, pp. 615-627, 1995.

[38] M. Rajarajan, B.Rahman, T. Wongcharoen, and K. Grattan, "Accurate analysis of MMI devices with two-dimensional confinement," Journal of Lightwave Technology, vol. 14, no. 9, pp. 2078-2084, 1996.

[39] A. Hosseini, D. N. Kwong, C. Y. Lin, B. S. Lee, and R. T. Chen, "Output formulation for symmetricallyexcited one-to- $N$ multimode interference coupler," IEEE Journal of Selected Topics in Quantum Electronics, vol. 6, no. 1, pp. 53-60, 2010.

[40] Optokon, "SFT-P series $1 \times N$ Planar Optical Splitter," Optokon Co., Ltd., Czech Republic, CPL_01-05_EN, Feb. 9, 2009. 